\title{
Customization of Human-Computer Interface Guided by Ontological Approach in Web 2.0
}

\author{
Yasyn ELYUSUFI \\ Laboratory LIROSA \\ FS-Tetouan \\ Tetouan-Morocco
}

\author{
Hamid SEGHIOUER \\ Laboratory LIROSA \\ FS-Tetouan \\ Tetouan-Morocco
}

\author{
Abdelhamid BENKADDOUR \\ Laboratory LIROSA \\ FS-Tetouan \\ Tetouan-Morocco
}

\begin{abstract}
The philosophy of web 2.0 applications is based on the democratization of access to information by providing the users, having humble technical knowledge, with the possibility to participate and improve web functions. In this very context figures this article, which is part of a series of research conducted by the team within the framework of the development of web 2.0 and participatory design of web interfaces. It aims at proposing a new design technique of web interfaces through involving the user in all stages of this process. In this respect, the internet users' contributions will be quite useful in web interfaces design by answering the questionnaires suggested by the system. These questionnaires will be integrated within ontology of the domain of human-computer interface ergonomics. The answers to the suggested questionnaires will allow a semantic classification of profiles according to a vector model and, then, develop ontology of users. Accordingly, the system will be able to categorize users in a definite profile based on their ergonomic interests and make a decision about the interfaces recommended by each type of profile. This article consists of three sections. In the first section, HCI technologies related to web 2.0 are presented. Secondly, participatory design and interface evaluation methods will be discussed. In the third section, HCI evaluation model guided by an ontological approach will be advanced in order to help the system make decisions about interfaces. The conclusion comes in the last section.
\end{abstract}

\section{General Terms:}

HCI, Ontology

\section{Keywords:}

HCI, Web 2.0, Ontology, Semantic Web, Ergonomics

\section{Introduction}

Web 2.0 was introduced in 2004 by Tim O'Reilly [1]. This concept has revolutionized the use of web sites and their applications. The internet user has shifted from a simple content consumer on the net into an active producer [2]. The concepts of web 2.0 have led to the development of web communities, such as social networks, video-sharing websites, wikis, blogs ..., introducing massive changes in the use of web. In the same context, T.O'Reilly describes in [3] the characteristics of web 2.0 by valuing the user as an active player in the web site content; as a result, he becomes the creator and consumer of information. C.Rizza states in [4] that the development of user ergonomics in Web 2.0 has highlighted the emergence of a range of technologies, especially RIA (Rich Internet Applications). Such technologies mark a new generation of interfaces responding to the development of the internet users' needs. However, the user's contribution in the design and evaluation of these interfaces remain a domain to be developed. J.Karat describes in [5] that distinction could be made between two methods for interface evaluation: methods that directly involve the user UBE (User -Based Evaluation) and evaluation methods based on task TBE (Task - based evaluation). In this context, evaluating human-computer interface based on the first method (UBE), and taking advantage of the internet users' contribution to evaluate the HCI is suggested. This evaluation will help design a pleasantly accepted interface by each category of users. These categories will be determined by the system based on the ergonomic interest of the internet users and the evaluation of the interfaces. This evaluation consists in comparing the model of the object being evaluated with a reference model. The ontology approach is used to create a reference model in the form of ontology of human-computer interface ergonomics. To implement this technique, questionnaires are adopted to be directly linked to this ontology. The proposed system is based on a successive generation of questionnaires whose answers will then allow the same system to classify the internet users in light of ergonomic interests. To draw up a semantic classification of profiles, Daoud and L. Tamine - Lechani present in [6] each category of users in a vector $\mathrm{V}$ model that will be used later for a semantic classification of the profiles. In this work an algorithm based on the vector model to build up ontology-based profiles is adopted and to be used later to help the system recommend customized interfaces for the constructed profiles.

\section{Web 2.0 and HCI}

R.Akrout states in [7] that a web application today is not limited to a simple web server managing a set of HTML pages. It uses relatively complex technologies that are constantly evolving, notably the RIA (Rich Internet Applications). On the other hand, C.Rizza defines in [4] RIA as a new generation of interfaces and applications which 
meet the changing users' needs. The key point of this evolution lies in the metaphor of richness:

\section{—Richness in content presentation \\ -Richness of navigation \\ -Richness of ergonomics}

C.Rizza says that the particularity of RIA consists in a set of concepts among which are concepts of users, Web 2.0, ergonomics and usability. In this sense, R. Stewart states in [8] that the RIA also has the advantage of "portability" which enables to find an application online from any workstation. Certainly, the development of technologies dedicated to improving the ergonomics of web interfaces is one of the foundations of Web 2.0 , and they do develop exponentially. However, the application of these technologies requires the user's evaluation which follows the ergonomics rules (effectiveness, ease of use, reliability ... ). To address this issue, a participatory evaluation of interfaces guided by ontology will be followed in this work, where the user is the main actor throughout this process.

\section{Techniques of participatory design and evaluation}

W Mackay defines participatory design in [9] as follows: "participatory design involves users throughout the design process. The users participate as experts in the use of technology, and as innovators contributing ideas which allow exploring new paths of design". There are several techniques for human-computer interface evaluation which include :

\section{—Brainstorming \\ —Design walkthrough \\ —Questionnaires}

N. W. Kohn, P. B. Paulus and YunHee Choi state in [10] that brainstorming is a specific process of creative search for ideas. This process can be reused several times while searching for ideas. However, it turns out to be very difficult to analyze the verbal reports presented by the large mass of internet-users for Web2.0 applications (social network, wiki ...). On the other hand, T. Goel cites in [11] that design walkthrough allows designers to quickly validate the design decisions relating to the user interface. It also enables designers to quickly identify and check if the suggested design meets the users' requirements. In this approach it is not practical to use this method due to the large mass of target participants in this work (wide audience). Further, the Design Walkthrough requires a specialized community made up of instructional designers and graphic experts. [Nielsen 93] shows that questionnaires allow collecting the users' impressions and determining their satisfaction or anxiety [12]. In addition to that, J. Karat explains in [5] that questionnaires are the easiest and cheapest way to collect data on the interface. Nevertheless, the process of manually entering answers can be long and often the user has fuzzy ideas about his interests; therefore, it is difficult to clearly express their intentions. To solve this problem the following approach is adopted, i.e to make the user choose between the proposals suggested by the system (cf. Table 1). These suggestions will be predefined by experts of specific domains (sociologists, designers, experts ...), and will be described in terms of the domain ontology where each questionnaire concerns a subject (class) of ontology.
Table 1. Example of questionnaire answers

\begin{tabular}{|l|l|}
\hline Question & Responses \\
\hline Do you want the & User $1: 3$ \\
main menu to be : & User $2: 1$ \\
1. Right & User $3: 2$ \\
2. Left & User $4: 3$ \\
3. Up & User $5: 1$ \\
4. Down & User $6: 2$ \\
\hline
\end{tabular}

\section{Ontology use}

K. M. Oliveira and F. Bacha cite in [13] that ontologies have been exploited in many studies and domains (medicine : Arsene, Dumitrache, and Mihu 2011 [14]; Rodriguez-Gonzalez 2012 [15]; Zhouet 2004 [16]), (education: Chu, Lee, and Tsai 2011 [17]; Jia 2011 [18]; Macrics and Georgakellos 2006 [19]; Versin, Ivanovic, Klasnja-Milicvic,and Budimac, 2012 [20]); and (logistics: Anand, Yang, van Duin, and Tavasszy, 2012 [21]; Gimnez, Vegetti, and Henning, 2008 [22], Grubic and Fan, 2010 [23] ) using their capacity to promote sharability of knowledge bases, knowledge organization, and interoperability between systems. On the other hand, K.Shahzad states in [24] that ontologies are used in information systems at various levels, such as database integration, business logic or user interface construction. The ontology-based model proposed allows determining the best design relating to the users' needs. This model is based on multiple-choice questionnaires. The answers submitted will be used to classify the internet users according to their ergonomic interests and, then, make a decision on the recommended interfaces. The ontology proposed constitutes a domain of $\mathrm{HCI}$ ergonomic subjects (usability, guidance, comfort ...), where each subject constitutes an ontology class relating to a set of questionnaires. The interaction process between the user and the system will allow classifying users based on their responses to the questionnaires. These answers will allow the system to predict the level of user's satisfaction regarding the interface design (cf Fig 11). Afterwards, the system classifies the users with a similar interest in various ontology subjects (classes), i.e. the users who provided answers identical to a percentage which will be defined later.

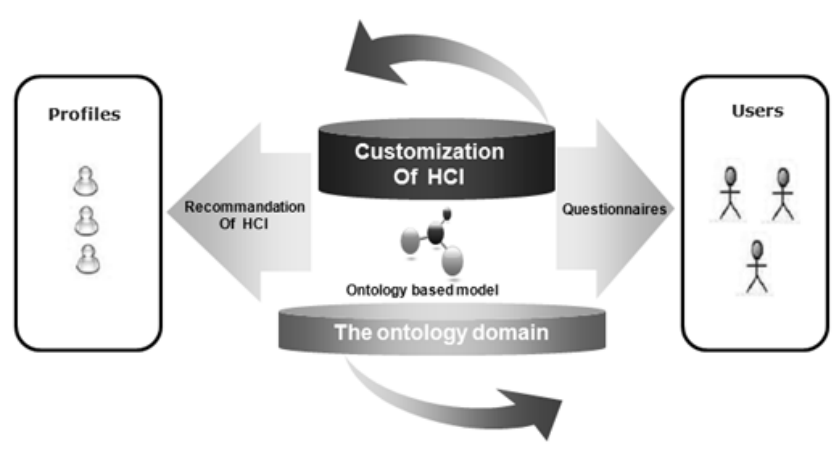

Fig. 1. The proposed architecture 


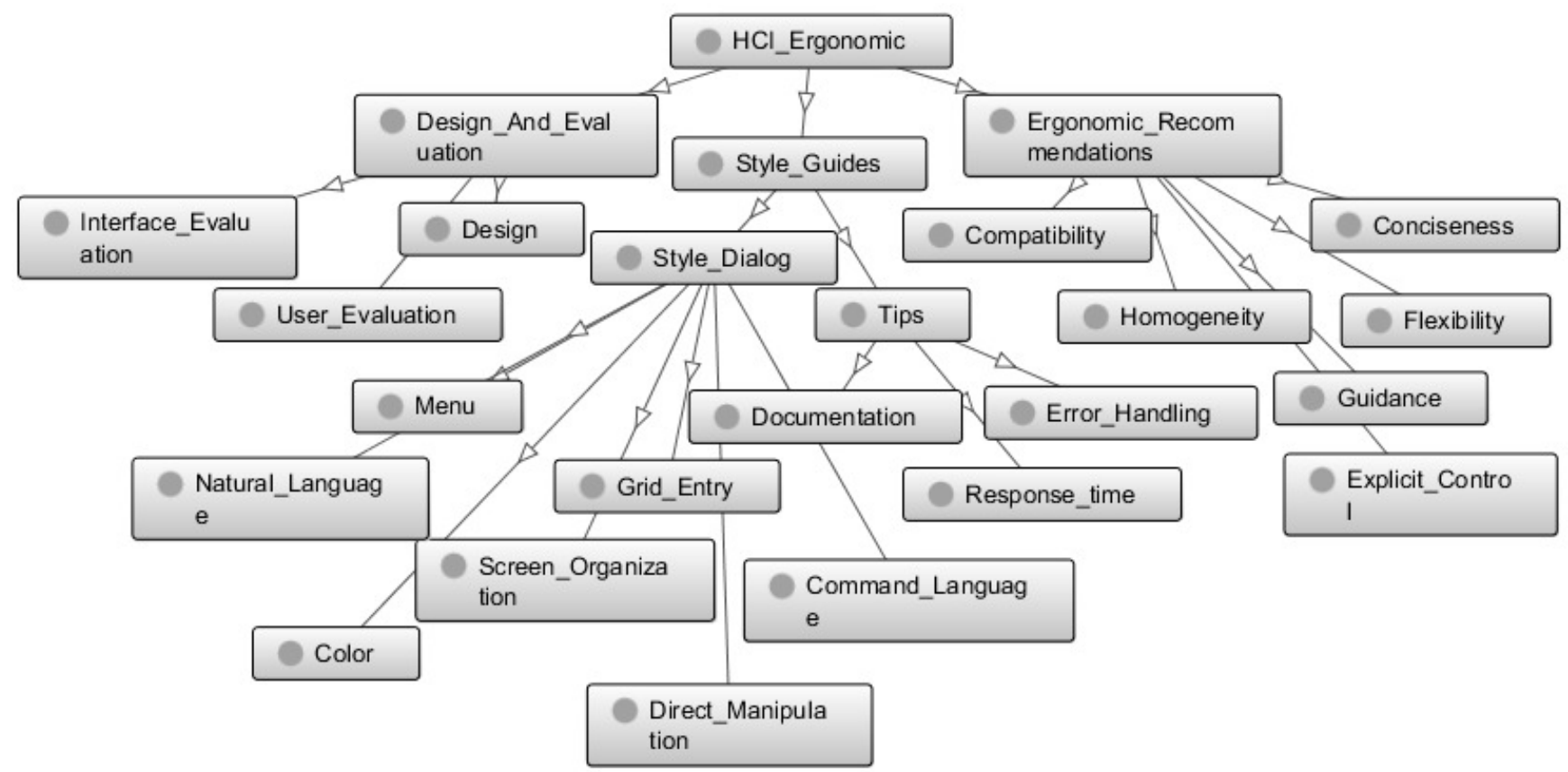

Fig. 2. Descriptive diagram of a part of ontology domain

\section{Ontology application: ontology of domains (HCI ergonomics)}

The ontology used represents the knowledge field of HCI ergonomics. It will allow users to express interests by responding to questionnaires (cf. Fig 2). The ontology presented should be designed by a community specializing in the field of HCI ergonomics. This Ontology is formed of several parts among which are:

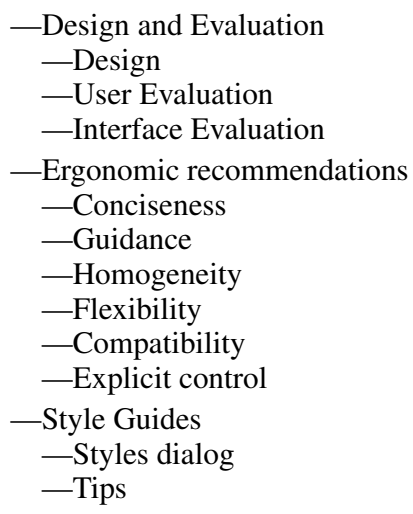

In this representation of the responses introduced by a sample of users for the ontology class (Flexibility) (cf.Table 2), it is noticed that the answers of the users 2 and 5 are $100 \%$ identical on the subject (Flexibility). These answers will help classify the internet users according to their levels of satisfaction. On the other hand, all responses will reveal weaknesses and flaws of interface design. This will enable classifying the users' categories according to the profiles which will be built up later.
Table 2. Example of users' responses

\begin{tabular}{|c|c|c|c|}
\hline User & Q1 & Q2 & Q3 \\
\hline User1 & 1 & 2 & 1 \\
\hline User2 & $\mathbf{2}$ & $\mathbf{2}$ & $\mathbf{3}$ \\
\hline User3 & 3 & 2 & 1 \\
\hline User4 & 1 & 2 & 3 \\
\hline User5 & $\mathbf{2}$ & $\mathbf{2}$ & $\mathbf{3}$ \\
\hline User6 & 2 & 1 & 2 \\
\hline
\end{tabular}

\section{Construction of ontology-based user profile}

M.Daoud and L.Tamine-Lechani present in [6] an implicit construction approach of profiles for an ontology-based customized information research. In the same context, an ontology-based customized interface will be proposed. The aim is to represent each user as a vector $\mathrm{V}$ model which will be used later for a semantic classification of profiles. To establish an accurate classification, the choices of answers are set in a matrix form where the weight $\omega_{i j}$ of option belongs to the matrix of choices $C$ (1).

$$
C_{i j}=\left(\begin{array}{ccc}
C_{11} & \ldots & C_{1 n} \\
\vdots & \ddots & \vdots \\
C_{p 1} & \ldots & C_{p n}
\end{array}\right)_{\substack{1 \leq i \leq p \\
1 \leq j \leq n}}
$$

The weight $\omega_{i j}$ of the term $C_{i j}$ is calculated as follows 2 :

$$
\omega_{i j}=10^{i}+j
$$

The base 10 is used to create a step of difference between the choices of questionnaire. 
Table 3. Table of assigned weights for each answer suggested by the system

\begin{tabular}{|c|c|c|c|c|c|c|c|c|c|}
\hline Topic & \multicolumn{3}{|c|}{ Menu } & \multicolumn{3}{c|}{ Color } & \multicolumn{3}{c|}{ Flexibility } \\
\hline Choice & $Q_{k}$ & $Q_{2}$ & $Q_{3}$ & $Q_{4}$ & $Q_{5}$ & $Q_{6}$ & $Q_{7}$ & $Q_{8}$ & $Q_{9}$ \\
\hline Choice1 & 11 & 12 & 13 & 14 & 15 & 16 & 17 & 18 & 19 \\
\hline Choice2 & 101 & 102 & 103 & 104 & 105 & 106 & 107 & 108 & 109 \\
\hline Choice3 & 1001 & 1002 & 1003 & 1004 & 1005 & 1006 & 1007 & 1008 & 1009 \\
\hline Choice4 & 10001 & 10002 & 10003 & 10004 & 10004 & 10006 & 10007 & 10008 & 10009 \\
\hline
\end{tabular}

The columns of the choice matrix $\mathrm{C}$ present the questionnaire vectors $Q_{j}$ (3) where the $j$ th column of the matrix C defines the questionnaire vector $Q_{j}$.

$$
Q_{j}=\left(\begin{array}{c}
C_{1 j} \\
\vdots \\
C_{p j}
\end{array}\right)_{(1 \leq j \leq n)}
$$

After collecting all users' responses the choice made by each user $V_{i}$ is presented (4) where each term $t_{i j}$ belongs to the matrix of choices (1).

$$
V_{i}=\left(\begin{array}{lll}
t_{i 1} & \ldots & t_{i n}
\end{array}\right)_{(1 \leq i \leq l)}
$$

$V_{i}:$ Is the user representative vector.

$t_{i j}$ : Designates the term $t_{i j}$ in the representative vector of a user $V_{i}$.

$l$ : Represents the number of users who have done the questionnaires.

The classification of users according to profiles consists in measuring the similarity between the user representative vector $V_{i}$ and other users' vectors with identical weight terms $t_{i j}$ term by term. Then, a parameter $\mathrm{P}$ is introduced which measures the percentage of similarity between the vectors. This parameter is calculated using the formula $(5)$ :

$$
P\left(V_{i}\right)=\frac{\left(N_{i} * 100\right)}{M}
$$

Where :

$-N_{i}$ : Refers to the number of terms identical to the user representative vector $V_{i}$.

-M: refers to the number of terms of the user representative vector that corresponds to the total number of questionnaires.

Users who provide the same answers for a number of questionnaires with a $\mathrm{P}\left(V_{i}\right) \geq 80 \%$, will be classified in the same profile. Generalizing this process to the terms of the vectors representing choices for different questionnaires, similar profiles can be obtained and, consequently, the interests relating to each type of profile. This representation is, then, used in order to customize the interfaces presented to the users, particularly through recommending interface elements which meet the chosen ergonomic interests expressed earlier. These interests will be described later as a user ontology to help the system make a decision on the recommended interfaces.

\section{Experimental results}

This evaluation scenario consists in evaluating the system with $l=$ 20 users. Each user must answer a triplet of questionnaires for three different subjects (Menu, Color and flexibility) $n=9$ where the user chooses between the suggested answers by the system. Four multiple choices $p=4$ are presented for each questionnaire. Table (cf. Table 3 ) shows the weights assigned to each answer given by the system.

The preliminary results show, overall, that the model enables filtering users who have provided answers similar to a percentage. Table 4 shows that the users 2, 5 and 11 have chosen the same answers in 8 questionnaires out of 9 . This indicates that they belong to the same profile with a percentage of $88.88 \%$. On the other hand, the users who do not belong to any profile will be treated according to their choices of answers during the evaluation. This allows the system to recommend interface elements which meet the specific needs of the evaluated ergonomic subjects. These results will be displayed later in the form of user ontology which will be presented using the ontology editor Protege, version 4.3.0 (cf. Fig 3).

Thanks to the meta data presented at the level of user ontology, the system recognizes the ergonomic interests for each type of profile. For instance, selecting the users V2, V5 and V11 belonging to the profile $\mathrm{P} 1$ whose terms of the user profile $\mathrm{P} 1(11,102,13,1004,105$, $16,107,10008,19)$ shows the choices of users 2,5 and 11 , where each term value designates a profile property (cf. Fig 4 ).

-Menu $1=11=$ property 1 .

- Menu2 $=102=$ property 2.

- Menu3 $=13=$ property 3 .

- Color $1=1004=$ property 4 .

- Color $2=105=$ property 5 .

-Color $3=16=$ property 6 .

-Flexibility $1=107=$ property 7 .

-Flexibility $2=10008=$ property 8 .

-Flexibility $3=19=$ property 9 .

The users who do not belong to any profile will be handled directly on the basis of their answers. In fact, the system will be able to recommend customized interface elements in relation to the evaluated subjects (Menu, Color and Flexibility ...) which meet the users' needs. 
Table 4. Table of users' choices

\begin{tabular}{|c|c|c|c|c|c|c|c|c|c|}
\hline \multicolumn{1}{|c|}{ Topic } & \multicolumn{3}{|c|}{ Menu } & \multicolumn{3}{|c|}{ Color } & \multicolumn{3}{|c|}{ Flexibility } \\
\hline$V_{i}$ & $Q_{k}$ & $Q_{2}$ & $Q_{3}$ & $Q_{4}$ & $Q_{5}$ & $Q_{6}$ & $Q_{7}$ & $Q_{8}$ & $Q_{9}$ \\
\hline$V_{1}$ & 101 & 1002 & 13 & 10004 & 15 & 1006 & 107 & 108 & 19 \\
\hline$V_{2}$ & $\mathbf{1 1}$ & $\mathbf{1 0 2}$ & $\mathbf{1 3}$ & $\mathbf{1 0 0 4}$ & $\mathbf{1 0 5}$ & $\mathbf{1 6}$ & $\mathbf{1 0 7}$ & $\mathbf{1 0 0 0 8}$ & $\mathbf{1 9}$ \\
\hline$V_{3}$ & 11 & 12 & 1003 & 14 & 1005 & 1006 & 107 & 1008 & 109 \\
\hline$V_{4}$ & 101 & 12 & 10003 & 14 & 105 & 106 & 1007 & 108 & 1009 \\
\hline$V_{5}$ & $\mathbf{1 1}$ & $\mathbf{1 0 2}$ & $\mathbf{1 3}$ & $\mathbf{1 0 0 4}$ & $\mathbf{1 0 5}$ & $\mathbf{1 6}$ & $\mathbf{1 0 7}$ & $\mathbf{1 0 0 0 8}$ & 109 \\
\hline$V_{6}$ & 101 & 102 & 13 & 104 & 15 & 106 & 1007 & 1008 & 19 \\
\hline$V_{7}$ & 1001 & 12 & 13 & 1004 & 15 & 106 & 1007 & 18 & 19 \\
\hline$V_{8}$ & 11 & 1002 & 1003 & 104 & 1005 & 16 & 17 & 1008 & 19 \\
\hline$V_{9}$ & 101 & 1002 & 13 & 1004 & 1005 & 106 & 1007 & 108 & 19 \\
\hline$V_{10}$ & 11 & 102 & 13 & 14 & 15 & 106 & 107 & 108 & 19 \\
\hline$V_{11}$ & $\mathbf{1 1}$ & $\mathbf{1 0 2}$ & $\mathbf{1 3}$ & $\mathbf{1 0 0 4}$ & 15 & $\mathbf{1 6}$ & $\mathbf{1 0 7}$ & $\mathbf{1 0 0 0 8}$ & $\mathbf{1 9}$ \\
\hline$V_{12}$ & 101 & 1002 & 1003 & 1004 & 15 & 106 & 1007 & 18 & 109 \\
\hline$V_{13}$ & 1001 & 1002 & 13 & 14 & 105 & 1006 & 17 & 18 & 1009 \\
\hline$V_{14}$ & 11 & 1002 & 13 & 104 & 15 & 106 & 107 & 18 & 19 \\
\hline$V_{15}$ & 1001 & 102 & 1003 & 1004 & 15 & 106 & 1007 & 10008 & 109 \\
\hline$V_{16}$ & 101 & 102 & 13 & 1004 & 15 & 106 & 107 & 10008 & 1009 \\
\hline$V_{17}$ & 1001 & 102 & 1003 & 1004 & 105 & 106 & 1007 & 10008 & 109 \\
\hline$V_{18}$ & 101 & 1002 & 1003 & 104 & 1005 & 16 & 17 & 1008 & 19 \\
\hline$V_{19}$ & 11 & 102 & 13 & 14 & 105 & 106 & 107 & 1008 & 1009 \\
\hline$V_{20}$ & 101 & 102 & 13 & 104 & 15 & 106 & 1007 & 108 & 109 \\
\hline & & & & & & & & & \\
\hline
\end{tabular}

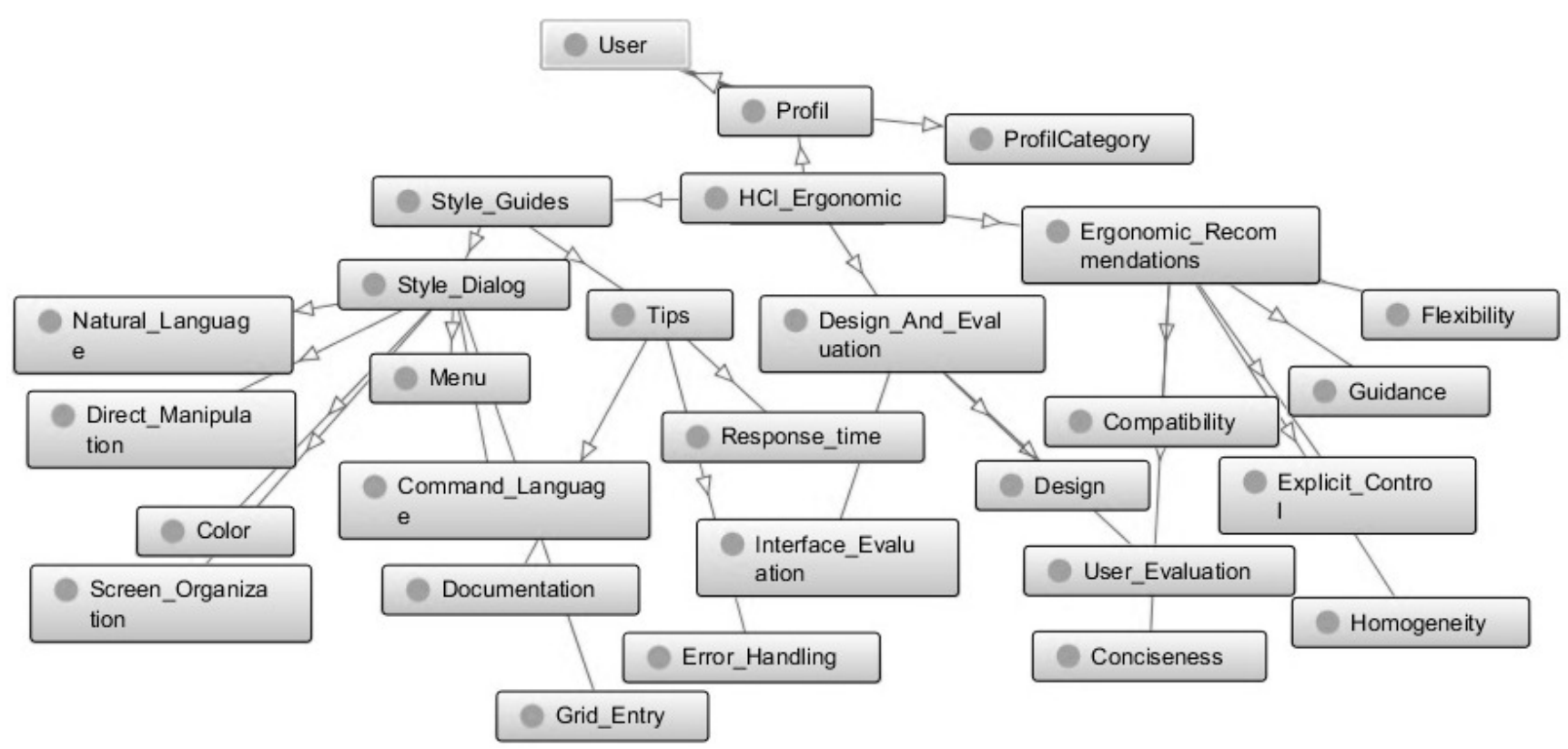

Fig. 3. Diagram of user ontology

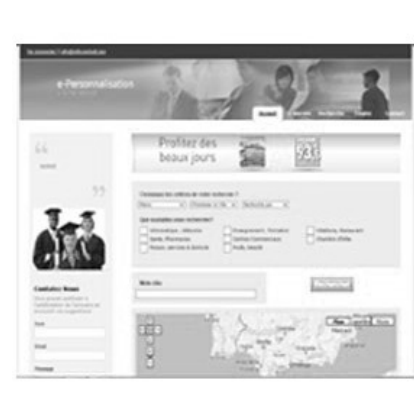

A - Default profile

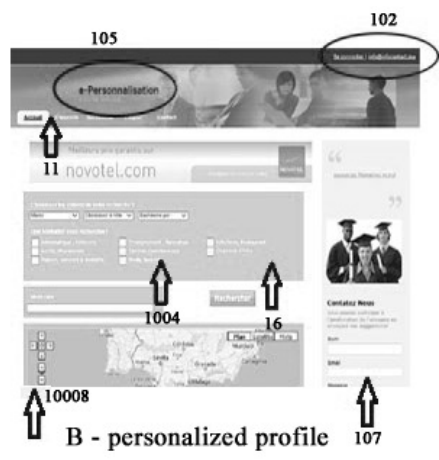

\section{Conclusion}

This work presents a method that aims to involve the user in the design and evaluation of Web 2.0 interfaces. This method allows the internet users to contribute in HCI design and evaluation. The choice of questionnaires related to domain ontology of HCI ergonomics was made to take advantage of the users' contribution in HCI evaluation and improvement. The method is based on 
measuring the similarity between the associated vectors to users in order to categorize users who have ergonomic interests similar to a defined percentage. Then, ontology-based user profiles were established to help the system make a decision on the recommended interfaces for each type of profile. Future work will develop domain ontology of $\mathrm{HCI}$ ergonomics using a multi-agent system, and then assess the impact of agents on the evaluation performance and participatory design.

\section{References}

[1] T.O'Reilly, 2005. [Online]. Available : 'http://oreilly.com/web2/archive/what-is-web-20.html'

[2] J.Gervais, Web 2.0 : ' les internautes au pouvoir, Dunod, 2007'.

[3] T.O'Reilly. (2005) : 'What is Web 2.0. Design patterns and business models for the next generation of software'.

[4] C. Rizza, S. Mahmoud :'The potential of Web 2.0 in the field of learning'

[5] Karat J., Software Evaluation Methodologies, Chap 41 : Handbook of Human-Interaction M.Helander (ed); Elsevier Science Publisher B.V. (North-Holland), 1988.

[6] M. Daoud, L.T. Lechani, M. Boughanem, B. Chebaro : 'Construction of profiles for an ontology-based customized information research, French Information Research and Applications (CORIA 2008) Tregastel: France (2008)'.

[7] R. Akrout Phd Thesis : 'Vulnerability analysis and evaluation of intrusion detection systems for Web applications, University of Toulouse 1, January 1997'.

[8] R. STEWART (2008). RIAs: 'Rich Learning for Higher Education. [December, 2008].

[9] W.E.Mackay (2002) :'Conception Participative et Evaluation des Interfaces Homme-Machine, Tutorial, Confrence Francophone d'Interaction Homme-Machine (IHM 2002), Poitiers'.

[10] P. B. Paulus, YunHee Choi :'Building on the ideas of others: An examination of the idea combination process, Elsevier Science Publisher, Nicholas W. Kohn Volume 47, Issue 3, May 2011, Pages 554-561'.

[11] T. Goel 2009 : 'An Effective Design Walkthrought : A step towards Delivring the best Design', Conference in New Delhi, November, 2010.

[12] Nielsen J., Usability Engineering, Academic Press Inc.,ISBN 0-12-518405-0, 198

[13] K. M. Oliveira: Transportation ontology definition and application for the content personalization of user interfaces, Elsevier Science Publisher, Expert Systems with Applications 40 (2013) 3145-3159.

[14] Arsene, O., Dumitrache, I., and Mihu, I. (2011). Medicine expert system dynamic Bayesian network and ontology based. Expert Systems with Applications, 38, 15253-15261.

[15] Rodriguez-Gonzalez, A., Torres-Nino, J., Hernandez-Chan, F., Jimenez-Domingo, E., and Alvarez-Rodriguez, J. (2012). Using agents to parallelize a medical reasoning system based on ontologies and description logics as an application case. Expert Systems with Applications, 39, 13085-13092.

[16] Zhou, X., Wu, Z., Yin, A., Wu, L., Fan, W., and Zhang, R. (2004). Ontology development for unified traditional Chinese medical language system. Artificial Intelligence in Medicine, $32,1527$.
[17] Chu, C., Lee, C., and Tsai, R. (2011). Ontology technology to assist learners navigation in the concept map learning system. Expert Systems with Applications, 38, 1129311299.

[18] Jia, H., Wang, M., Ran, W., Yang, S., Liao, J., and Chiu, D. (2011). Design of a performance-oriented workplace e-learning system using ontology. Expert Systems with Applications, 38, 33723382.

[19] Macrics, A., and Georgakellos, D. A. (2006). A new teaching tool in education for sustainable development: Ontology-based knowledge networks for environmental training. Journal of Cleaner Production, 14, 855867.

[20] Versin, B., Ivanovic, M., Klasnja-Milicvic, A., and Budimac, Z. (2012). Protus 2.0:Ontology-based semantic recommendation in programming tutoring system.Expert Systems with Applications, 39, 1222912246.

[21] Anand, N., Yang, M., van Duin, J. H. R., and Tavasszy, L. (2012). GenCLOn: An ontology for city logistics. Expert Systems with Applications, 39, 1194411960.

[22] Gimnez, D. M., Vegetti, M., Leone, H. P., and Henning, G. P. (2008). Product ontology: Defining product-related concepts for logistics planning activities. Computers in Industry, 59, 231241.

[23] Grubic, T., and Fan, I. (2010). Supply chain ontology: Review, analysis and synthesis.Computers in Industry, 61, 776786.

[24] S. K Shahzad: 'Ontology-based User Interface Development: User Experience Elements Pattern, vol. 17, no. 7 (2011)'.

[25] L. Jayasimman:' Dynamic User Interface Based on Cognitive Approach in Web Based Learning, Vol. 8, Issue 4, No 1, July $2011^{\prime}$. 